\title{
Retrospective Observations Made by Parents of Children with Anorexia Nervosa about Early Food Selection-A Qualitative Study
}

\author{
Barbara Scolnick*, Julie Ramsey, Inbar Hanouna, Caroline Holcomb, Candace \\ Walsh, David I Mostofsky \\ Department of Psychology, Boston University, Boston, MA, USA
}

\begin{abstract}
Received: January 19, 2015; Accepted: February 22, 2015; Published: March 18, 2015
*Corresponding author: Barbara Scolnick, Department of Psychology, Boston University, 64 Cummington Street, Boston, MA 02235, USA, Tel: +1-617803-6353; E-mail: scolnick@bu.edu
\end{abstract}

\begin{abstract}
Objective: We sought hypothesis generating data regarding food choices in childhood, and subsequent development of anorexia nervosa, by examining the retrospective observations of parents regarding their child's early pre-morbid food selection and eating style.

Method: We conducted open-ended interviews of 20 parents of children with anorexia nervosa, and did a qualitative analysis of the interviews. We then developed an online questionnaire that 16 parents filled out, and incorporated that data into the analysis.

Results: The vast majority of parents reported their child was a "good" eater with a healthy appetite. When asked if the child's eating seemed "different," many reported they had displayed an unusually mature and adventurous palate. Families were aware of healthy eating recommendations. Recognition of early subtle symptoms was difficult, and almost all their child's initial interest in exercise and "healthy eating" that delayed the diagnosis.

Discussion: Since the observations and insights of parents have been neglected for many years, these observations challenge the historical focus on "picky eaters" as a risk factor for anorexia nervosa, and suggest the alternative unusually adventurous and "carefree" food selection may be a risk factor. The subtle onset of the disorder should be more widely publicized especially to parents and pediatricians.
\end{abstract}

\section{Introduction}

Determining risk factors for the development of Anorexia Nervosa (AN) is a challenge for many reasons: longitudinal studies often lack sufficient power, case/control studies have unavoidable retrospective bias, and patients with AN usually suffer from distorted thinking which decreases the validity of their observations [1]. Adding to the difficulty, for many years, parents were thought to be responsible for causing their child's disorder, and thus were considered unreliable, and their input on risk factor analysis was not sought [2]. Since it was assumed that psychological factors caused AN, there was little emphasis on examining food selection as a factor. Our aim, in this exploratory qualitative study, was to fill in these gaps in the AN literature by questioning parents in a open- structured interview format, focusing on the early food and eating behavior of the child, and parents' first suspicions something was amiss as their child became ill. Our guiding questions were: How did the child and family function around food? What foods did they eat before onset? How did they eat meals? What happened during the period between early symptoms and treatment?

\section{Methods}

\section{Participants}

Twenty parents were recruited through online parent support groups, local eating disorder clinics, and private therapist offices. We recruited 16 parents through an Internet parent support group called Around The Dinner Table (ATDT); three were from local therapist offices, and one heard about the study from a friend. ATDT is supported by an international non-profit charity, FEAST (Families Empowered and Supporting Treatment of Eating Disorders) whose express purpose is supporting parents and caregivers to help loved ones recover from eating disorders. All the patients had restricting AN as the primary diagnosis with three of them exhibiting episodes of binging and purging during recovery. As summarized in Table 1, there were 3 males, 17 females and the median age of diagnosis was 14 years, with a range of 9-19. All were white, and middle class. Only one parent reported their child was recovered; one child continued to suffer with severe symptoms for the duration of the study (October 2012-October 2014), two were in active relapse, one was slowly improving, and 15 were "on their way" to recovery. The average time from diagnosis to participating in the interview was 19 months, with a range of 6 months to 5 years.

The majority of the interviews were approximately two hours; most interviews were conducted by telephone; all interviews, whether in person or via telephone, were recorded and transcribed. The Boston University Institutional Review Board approved this protocol, and all parents signed an informed consent, or gave consent over a recorded line. 


\section{Assessment}

Two senior clinicians and three graduate students in psychology performed all the interviews. The aim was to have the parent "tell their story": how they remember their child growing up, how the child and family ate, what foods they usually ate, how they suspected something was amiss, and how the diagnosis of AN was made. A partial list of questions is noted in Table 2.

After completing twenty interviews we developed a 150-question survey to ensure our questions of interest were answered by most of the participants. A partial list of questions is on Table 2. Most questions were rated on a 5 part-Likert scale. Almost every question had unlimited room for writing in comments. We then requested the participants fill out the questionnaire over the Internet.

\section{Procedure}

Sixteen parents filled out the survey, and all made extensive use of the comments section. The qualitative transcripts and written comments were read and reread by two of the authors (JR and BS) who individually grouped the data into thematic categories, following principles of content analysis [3]. We then collaborated and compared our coding. We had generally similar themes; where there were inconsistencies we reread the data until we came to an agreement. We knew we had achieved saturation of the data, when further rereading and recoding lead to no new categories [4].

\section{Results}

Twenty parents completed the interview, and of these 16 also answered the survey. The qualitative results from the interview plus write in data for the survey revealed four thematic categories:

\section{Families Relationship to Food \& Eating}

We found that all 20 of the interviewed families served home cooked meals, Nineteen of the twenty ate together at the dining room or kitchen table several times a week, and did not have the TV on during dinner. Several mentioned it was difficult to continue family dinners as regularly once middle school arrived and sports practices interfered. In 12 of 16 families questioned on the matter, at least one of the parents loved to cook.

None of the families were vegetarians. Seven of the 20 families reported one parent being on a diet at times or someone in the family struggling with their weight. None of the children ate diet foods or artificial sweeteners, but these products were in the house. Interestingly, none of the participants considered skim milk, low fat salad dressing, or low fat mayonnaise to be diet food. The usual drink at dinner was milk or juice. Only one family drank whole milk. Six children who had shown intolerance

Table 1: Demographics of Participants.

\begin{tabular}{|c|c|c|c|c|c|c|c|}
\hline Age onset & $\begin{array}{l}\text { Length of } \\
\text { illness }\end{array}$ & Sex & Status & Source & BMI lowest & $\begin{array}{c}\% \text { Body Weight } \\
\text { Lost }\end{array}$ & Parent \\
\hline 12 & $2 \mathrm{yr}$ & $\mathrm{F}$ & Recovered & Website & 14.8 & $9 \%$ & Mother \\
\hline 14 & 1.5 & F & Improving & Website & 19.1 & $24 \%$ & Mother \\
\hline 14 & $5 \mathrm{yr}$ & $\mathrm{F}$ & Relapsed & Website & 15.8 & $49 \%$ & Father \\
\hline 10 & $6 \mathrm{mo}$ & M & Improving & Website & 15.1 & $12 \%$ & Mother \\
\hline 13 & $2 \mathrm{yr}$ & $\mathrm{F}$ & Improving & Website & 17.8 & $15 \%$ & Mother \\
\hline 13 & $2 \mathrm{yr}$ & $\mathrm{F}$ & Improving & Therapist & 17.5 & $22 \%$ & Mother \\
\hline 15 & $9 \mathrm{mo}$ & $\mathrm{F}$ & Improving & Website & 14.7 & $16 \%$ & Mother \\
\hline 14 & $15 \mathrm{mo}$ & $\mathrm{F}$ & Improving & Therapist & 22.5 & $11.5 \%$ & Mother \\
\hline 13 & $18 \mathrm{mo}$ & $\mathrm{F}$ & Improving & Therapist & 15.6 & $21 \%$ & Mother \\
\hline 15 & $5 \mathrm{yr}$ & $\mathrm{F}$ & $\begin{array}{c}\text { Slowly } \\
\text { Improving }\end{array}$ & Friend & 14.6 & $34 \%$ & $\begin{array}{l}\text { Mother } \\
\text { Father }\end{array}$ \\
\hline 10 & $20 \mathrm{mo}$ & $\mathrm{F}$ & Improving & Therapist & & $22 \%$ & Mother \\
\hline 13 & $6 \mathrm{mo}$ & $\mathrm{F}$ & Improving & Website & & $11 \%$ & Mother \\
\hline 17 & $9 \mathrm{mo}$ & $\mathrm{F}$ & Improving & Website & 17.9 & $11 \%$ & Mother \\
\hline 19 & $8 \mathrm{mo}$ & M & Improving & Website & 16.5 & $18 \%$ & $\begin{array}{l}\text { Mother } \\
\text { Father }\end{array}$ \\
\hline 18 & $8 \mathrm{mo}$ & $\mathrm{F}$ & Improving & Website & 18.5 & $13 \%$ & Mother \\
\hline 14 & $20 \mathrm{mo}$ & $\mathrm{F}$ & Improving & Website & & $14 \%$ & \\
\hline 9 & $12 \mathrm{mo}$ & $\mathrm{F}$ & Improving & Website & & $35 \%$ & Mother \\
\hline 14 & 3 yrs & M & Improving & Website & & $20 \%$ & Mother \\
\hline 17 & $6 \mathrm{mo}$ & $\mathrm{F}$ & Improving & Website & 15.6 & $28 \%$ & Mother \\
\hline 19 & $21 / 2 y r$ & $\mathrm{~F}$ & Relapsed & Website & 16.4 & $14 \%$ & Mother \\
\hline
\end{tabular}

Citation: Scolnick B, Ramsey J, Hanouna I, Holcomb C, Walsh C, et al. (2015) Retrospective Observations Made by Parents of Children with Anorexia Nervosa about Early Food Selection-A Qualitative Study. Obes Control Ther 2(1): 1-5. DOI: http://dx.doi. 
Table 2: Interview Prompts; Questionnaire Sample.

\author{
Sample questions and prompts from Interview \\ Please describe your daughter/son eating as an infant, baby, toddler, and school aged child. Prompts: breast, bottle fed, starting solids, picky eater, \\ had a sweet tooth, concerns eating too much or too little \\ Did you notice her eating or food choices were different from her friends? \\ Could you tell me about the onset of her illness? Prompts Did she have any sickness, growth spurt, emotional trauma, difficulty in school, or \\ anything else that comes to mind that was going on about that time?
}

\title{
Sample questions from Questionnaire
}

(Answered on 5 point scale: agree strongly, agree slightly, neutral, disagree slightly, disagree strongly

Generally as a child he/she had limited repertoire of foods he/she would eat

Generally as a child he/she was willing to try new foods

As a child he/she had concerns about textures of food-too mushy etc

As a child he/she liked very spicy and strong flavors.

As a child you worried that he/she was eating too much and had concerns about portion control.

Most meals were home cooked

Generally chicken was eaten at least once/week

Someone in the family really enjoyed cooking

to cow's milk as toddlers continued to avoid it, substituting soy milk, goat milk, or juice. The remaining 13 drank only skimmed, $1 \%$, or $2 \%$ milk.

All the families allowed free access to the kitchen, and most reported their child began to select their own foods for snack at age 9 or 10. Most reported there were sweets in the house -it was most frequently ice cream, baked goods, and/ or cookies. All the families would eat out for dinner occasionally; 13 never ate at fast food restaurants, and 5 occasionally did.

Quotes that capture the responses are as follows:

- "We ate everything and anything; we were the AllAmerican family. We have a vegetable garden and there were frequently fresh vegetables."

- "We ate meat and potatoes, casseroles and salmon, everything in moderation. Meals were fun. We felt very lucky."

- "I loved to cook and did not like processed foods. If anything was different about our eating it was healthier than neighbors. I cooked everything from scratch."

- "I do not like to cook, but it's my job so I do it. Typically spaghetti one night, stuffed shells with meat sauce the next. Spaghetti from a jar, but there was always dinner on the table, and we ate together."

- "We live in rural area so we would go right to the farms, and ate what was in season."

- "It was so ironic that my daughter got an eating disorder, because I was the best cook of all my friends, and my family always enjoyed eating."

\section{Recall of Child's Early Food Selection}

Of the 20 children, 18 were breast fed for a period of three months to two years, with a median of nine months. As toddlers and young children eighteen of the 20 children were described as adventurous eaters, willing to try new foods, who surprised friends and family with their willingness to eat what are considered "healthy" or "adult" foods. Some quotes that capture the answers include:

"She adored beans with a passion. String beans, lentil, peas, People loved to have her sleep over because she was so easy to feed. She ate what the adults ate. She even liked hot peppers."

"Only difference from her peers, she ate healthier, did not like fries, and liked a good sirloin."

"Her eating was different from her sister who was a plain Jane. My husband would buy these pickled onions in vinegar, and she would pop them into her mouth like they were candy."

Two of the children were described as "picky"; they liked the same food everyday, no spice, and liked "white food" such as white bread without crust and macaroni and cheese.

\section{Recall of Child's Early Eating Behavior}

When asked to describe their child's satiety, ten of the twenty parents noted their child was "hungry all the time," "kept eating until the food was gone," and "ate everything." Of note, five of these children were described specifically as "over eaters" with parents noticing their challenges around regulation of food intake. Of these five, four had a parent who was on a diet. All 20 children were normal weight, although three were on the high end (one always tracked as heavier, one gained weight after becoming a vegetarian, and one gained weight at onset of puberty), and two were on the low end. Only one parent ever had concerns their child was not eating enough.

Most parents were surprised that this particular child developed AN, as the parents noted he/she always enjoyed eating and was a pleasure to feed.

\section{"My Child Changed Before my Eyes"}

The time between first noticing symptoms and the formal diagnosis of AN varied greatly. The symptoms noted by the parents (and in one case a coach) were food restriction, noted in 15 children; personality changes, noted in 7 children; weight loss, noted in 10 children; feeling cold all the time, noted in 6 children; 
stomach aches, noted in 1 child; excessive drinking of water, noted in 1 child; skin looking "grey," noted in 1 child; fainting, noted in 1 child; and hair loss, noted in 1 child.

It was very difficult for most parents to pinpoint the moment they became concerned, then alarmed. Many parents reported that the initial changes were very subtle; an unhappiness, an avoidance of friends, a desire to exercise, some obsessive symptoms, such as having to score a basket a specified number of times until he could allow himself to stop practicing, but it was difficult to see it as abnormal. Some parents thought their child was showing emotional signs of adolescence. Several children developed a strong interest in cookbooks and preparing food approximately two or three years before being diagnosed with anorexia nervosa. All reported the child developed an interest in healthy eating. Over $50 \%$ gave up foods such as desserts or "junk food;" sometimes these were given up for Lent. Many parents were initially delighted with these changes. Several parents noted their child took part in a school-based programs based around healthy eating and exercise. No one thought these programs were intrinsically causative, but instead saw their child as uniquely vulnerable. Seven children chose to become vegetarian several months to one year prior to diagnosis (only one was allowed to continue after diagnosis). This period of vague concern varied from six months or less, up to two years before the diagnosis was made.

\section{Other Observations}

Four parents spontaneously mentioned their children had a high pain threshold. Five parents noted their children had "sensory issues" such as intolerance of tags on clothes, etc. during their toddler years, which was unusual.

Six children had chronic prolonged (greater than 1 year continuous) antibiotic use throughout childhood - four for recurrent otitis media; one for recurrent pulmonary infections; one prophylaxis because she was on steroids.

\section{Discussion}

We were surprised that 18 out of 20 children were described as that flexible in their eating, able to try new foods, and considered to be "good eaters" during childhood. Several parents described their child as having an "adventurous" palate, and eating what the adults ate. This seems contrary to conventional wisdom which links "picky eating" in childhood to development of AN [5]. One early researcher, Arthur Crisp (1970) described that retrospectively parents reported children subsequently diagnosed with AN were "good eaters" [6]. After this early citation, research has focused only on "picky eaters." Two longitudinal studies which reported on the same cohort of 800 children from New York State followed from birth up to 30 years found a correlation between "eating conflicts, struggles with food, and unpleasant meals" and subsequent eating disorders [5,7]. These factors correlated with BN more strongly than AN, and the numbers were very small (only eight patients with probable AN were found). In another cohort of 11,262 children followed over 30 years, 101 cases of AN were identified [8]. In this group infant feeding problems and under-eating in later childhood appeared to be associated with the development of anorexia nervosa. It is possible that the association with under-eating in childhood may represent early onset of anorexia nervosa.

Several case/control studies have looked at early "picky eating" as a risk along with other risk factors, finding weak correlations [8-14]. It is important to recognize that parents were not included in development of the questionnaires frequently used in these studies, so the analysis was limited to the researcher's assumptions, which were derived from focus groups consisting of only researchers and patients. In 2011 Dellava examined retrospective maternal reports of early feeding difficulties, picky eating, and gastrointestinal symptom in a group of patients with AN [15]. Mothers were asked, "How often was your child a picky eater?" While the subject who filled out the questionnaire, was the mother rather than the patient, there was no parental involvement in the development of the instrument, and there were no questions examining other eating behaviors such as adventurous palates, or being unusually easy to feed. Dellava's results showed no association between early eating problems and subsequent AN; only $11 \%$ of the women with AN were described by their mothers as picky eaters. It is interesting that our results 2 out of $20(10 \%)$ were also described as picky.

A recent review of a population based cohort of 4,018 from Rotterdam, The Netherlands, noted that $46 \%$ of the children were "picky eaters" at some point before age 6 [16]. Noting that "picky eater" remains a vague concept, the authors defined it as a parent's positive answer to two questions; whether the child "does not eat well: or "refuses to eat." The authors note that "picky eating can be considered a normal developmental phase, and hypothesized the evolutionary advantage that "picky eating" as a youngster helps the child avoid toxins.

Is this "adventurous, mature palate" we were noticing, paradoxically indicative of immature taste development? Can it be that the food restriction in later childhood or early puberty that develops into AN is a delayed "normal" response that is occurring at a vulnerable developmental period?

We found that families appeared to be on the healthiest end of the continuum of ordered eating. They ate home cooked meals, were aware of eating seasonally, ate dinners as a family and were aware of "healthy eating." While this is laudable, we wonder whether the decreased milk intake might be significant. Only one of these children drank whole milk; most avoided fast foods, and were aware of limiting fat. These families were aware of nutritional recommendations. The 2006 American Academy of Pediatrics toddler recommendations are that a child be weaned from breast milk to skim milk if there is a family history of obesity [17].

We noted a substantial minority; six of the 20 (30\%) were on chronic prophylactive antibiotics for at least one year in early childhood. This is interesting in light of some evidence that gut microflora could act via the immune system to influence hypothalamic appetite regulating proteins [18]. 
Most parents reported being initially pleased that their child showed an interest in "healthy" eating and exercise, and cooking. Although widely appreciated in eating disorder clinics that this cluster of behavior can be an early warning of AN [19], none of the parents were aware of that initially.

\section{Limitations and Recommendations}

Our study included only 20 families, and they were all white, middle class and 16 were from one Internet site. This homogeneity raises questions about the generalizability of the findings to the wider population. There could be bias in how parents reported their families' very healthy relationship to food and eating. Another major limitation was there was no control group. Nevertheless, within these limitations, we think we have uncovered several testable hypotheses.

- Adventurous or mature food preference in early childhood is more common in children who go on to develop AN than in their peers.

- Families of children who develop AN follow nutritional guidelines more closely, than comparable families without a child with AN. This may cause limited fat intake.

- Prolonged antibiotic use in childhood is more common children who develop AN than in children without eating disorders. .

- School sponsored healthy eating programs are inadvertently increasing restrictive dieting in children who are primed to develop AN.

- Parents and pediatricians need more information about the early subtle symptoms and signs of anorexia nervosa, that are difficult to interpret when only focusing on prevention of childhood obesity.

\section{References}

1. Jacobi C, Hayward C, de Zwaan M, Kraemer HC, Agras WS. Coming to terms with risk factors for eating disorders: application of risk terminology and suggestions for a general taxonomy. Psychol Bull 2004; 130(1):19-65.

2. 2 Minuchin S, Fishman HC. The psychosomatic family in child psychiatry. J Am Acad Child Psychiatry. 1979;18(1):76-90.

3. Richards L. Handling Qualitative Data: A Practical Guide. London: Sage Publications; 2008.

4. Rajendran NS. Dealing with biases in qualitative research: a balancing act for researchers. Presented at: Qualitative Research Convention 2001: Navigating Challenges. 25-26 October 2001; Kuala Lumpur, Malaysia.

5. Marchi M, Cohen P. Early childhood eating behaviors and adolescent eating disorders. J Am Acad Child Adolesc Psychiatry 1990; 29(1):112-

6. Crisp AH. Reported birth weights and growth rates in a group of patients with primary anorexia nervosa (weight phobia). J Psychosom Res. 1970; 14(1):23-50.

7. Kotler LA, Cohen P, Daies M, Pine DS, Walsh BT. Longitudinal relationships between childhood, adolescent, and adult eating disorders. J Am Acad Child Adolesc Psychiatry. 2001; 40(12):1434-40.

8. Nicholls DE, Viner RM. Childhood risk factors for lifetime anorexia nervosa by age 30 years in a national birth cohort. J Am Acad Child Adolesc Psychiatry. 2009; 48(8):791-8. doi: 10.1097/ CHI.0b013e3181ab8b75.

9. Rastam M. Anorexia nervosa in 51 Swedish adolescents: premorbid problems and comorbidity. J Am Acad Child Adolesc Psychiatry. 1992; 31(5):819-29.

10. Fairburn CG, Cooper Z, Doll HA, Welch SL. Risk factors for anorexia nervosa: three different case-control comparisons. Arch Gen Psychiatry 1999: 56(5):467-76.

11. Karwautz A, Rabe-Hesketh S, Hu X, Zhao J, Sham P, Collier DA, et al. Individual specific risk factors for anorexia nervosa: a pilot study using a discordant sister-pair design. Psychol Med. 2001; 31(2):31729.

12. Micali N, Holliday J, Karwautz A. Haidvogl M, Wagner G, FernandezAranda F, et al. Childhood eating and weight in eating disorders: a multicentre European study of affected women and their unaffected sisters. Psychother Psychosom. 2007; 76(4):234-41.

13. Fernandez-Aranda F, Krug I, Granero R, Ramon JM, Badia A, Gimenez $\mathrm{L}$ et al. Individual and family eating patterns during childhood and early adolescence: an analysis of associated eating disorder factors. Appetite. 2007; 49(2):476-85.

14. Krug I, Treasure J, Anderluh M, Bellodi L, Celllini E, Collier D, et al. Associations of individual and family eating patterns during childhood and early adolescence: a multicentre European study of associated eating disorder factors. Br J Nutr. 2009; 101(6):909-18. doi: 10.1017/ S0007114508047752.

15. Dellava JE, Thornton LM, Hamer RM, Stober M, Plotnicov K, Klump $\mathrm{KL}$, et al. Childhood anxiety associated with low BMI in women with anorexia nervosa. Behav Res Ther. 2010; 48(1):60-7. doi: 10.1016/j. brat.2009.09.009.

16. Cardona Cano S, Tiemeier H, Van Hoeken D, Tharner A, Jaddoe VW, Hofman A, et al. Trajectories of picky eating during childhood: A general population study. Int J Eat Disord. 2015. doi:10.1002/ eat.22384.

17.17.Gidding SS, Dennison BA, Birch LL, Daniels SR, Gilman MW, Lichtenstein $\mathrm{AH}$ et al. Dietary recommendations for children and adolescents: A Guide for Practitioners Pediatrics. 2006; 117(2):54459.

18. Fettisov SO, Hamze SM, Coeffier M, Bole-Feysot C, Ducrotte P, Hokfelt T, Dechelotte P. Autoantibodies against appetite-regulating peptide hormones and neuropeptides: putative modulation by gut microflora. Nutrition. 2008; 24(4):348-59. doi: 10.1016/j.nut.2007.12.006.

19. Campbell K, Peebles R. Eating disorders in children and adolescents: state of the art review. Pediatrics. 2014; 134(3):582-92. doi: 10.1542/ peds.2014-0194. 